\title{
Which research can support PD facilitators? Strategies for content-related PD research in the Three-Tetrahedron Model
}

\author{
Susanne Prediger ${ }^{1}$ (D) $\cdot$ Bettina Roesken-Winter $^{2}$ (D) $\cdot$ Timo Leuders $^{3}$ (D)
}

Published online: 7 May 2019

(C) The Author(s) 2019

\begin{abstract}
Given the challenges of scaling up content-related professional development (PD), the PD facilitators have gained increasing attention in PD research. In this mainly programmatic and structural article, we try to systematize existing research strategies which take into account the multifaceted and multi-level structure of PD research. We discuss the lifting strategy which draws upon structural analogies between the classroom and the PD level, the nesting strategy for research-based design, and the unpacking strategy for design-based PD research and locate these strategies within a Three-Tetrahedron Model for PD research. Thereby, we present a framework to systematize and explain existing research approaches and to identify necessary but missing research contributions. The article provides a language for initiating a discourse on research agendas which can support PD facilitators: The Three-Tetrahedron Model for PD research and design captures the complexity of learning and teaching at the classroom, teacher, and facilitator level that is needed to inform design and research into PD as well as to uncover gaps in the literature.
\end{abstract}

Keywords Research agenda $\cdot$ Teacher professional development $\cdot$ Facilitator professional development $\cdot$ PD research $\cdot$ Lifting strategy $\cdot$ Nesting and unpacking strategy

In the last decades, the design of and research on professional development (PD) courses for in-service mathematics teachers have developed substantially. The focus has widened from design principles for and effects of single PD courses to scaling up PD and

Susanne Prediger

prediger@math.uni-dortmund.de

Bettina Roesken-Winter

bettina.roesken-winter@hu-berlin.de

Timo Leuders

leuders@ph-freiburg.de

1 Institute for Development and Research in Mathematics Education, TU Dortmund University,

Vogelpothsweg 87, 44227 Dortmund, Germany

2 Humboldt-Universität zu Berlin, Berlin, Germany

3 University of Education, Freiburg, Freiburg im Breisgau, Germany 
contributing both generic and content-specific research findings (Sowder 2007; Desimone 2009; Sztajn et al. 2017).

In the context of scaling up PD programs, there has been an almost complete lack of research in PD on the practices of facilitators (Jackson et al. 2015; Roesken-Winter et al. 2015). Some pioneering research studies have focused on facilitators' professional knowledge (Jaworski and Huang 2014; Even 2005; Borko et al. 2008) and practices (Borko et al. 2014; Lesseig et al. 2017; Jacobs et al. 2017). In addition, some research programs have aimed at identifying and investigating facilitation moves and have contributed descriptions of rather generic (i.e., less topic-specific) practices in facilitating PD (González et al. 2016). A few other research contributions have favored a more content-specific approach by implementing, for instance, the problem-solving cycle model into leadership preparation (Borko et al. 2014).

Given the wide consensus on the critical role of facilitators, it is time to systematically raise the programmatic question: What kind of research is required to inform PD facilitation in a research-based way? Thus, we draw on issues such as the following raised by Lesseig et al. (2017) that "we lack research-based principles to guide the design of leader preparation" (p. 592). By considering the interplay of research and design, we particularly emphasize their connections: PD design should be informed by research; hence, we talk about research-based PD design. Vice versa, PD research is always contextualized by the specific design of the PD, and we talk about design-based $P D$ research when the design is considered as an important part of the work of the researchers and is systematically included in the research activities (Cobb et al. 2003; Prediger 2019).

Particularly, we consider that both research-based PD design and design-based PD research must address the mathematics classroom level as well as the PD levels for teachers and facilitators (multi-level structure of PD), and it must focus on generic aspects as well as content-specific aspects for different PD contents. With respect to the content focus, Garet et al. (2016) have pointed out the problem that empirical evidence for the effect of PD on students' achievements is hard to achieve. As a conclusion, Garet et al. (2016) identified a "potential need to improve our understanding of the aspects of knowledge and practice that effective teachers should master" (p. 9/10). Based on the findings within three large-scale random assignment studies of teacher PD, they further underlined that "doing so will better enable developers to design PD that focuses on improving those aspects of knowledge or practice that will most likely translate into improvements in student achievement" (p. 1). In this article, we pay particular attention to such interplay of design and research and suggest strategies for specifying the PD content.

To allow for identifying necessary aspects of PD design and research, a model is required to capture the complexity of PD courses in a multifaceted way and to connect the different levels of (1) teaching and learning on the classroom level, (2) PD on the teacher level, and (3) PD on the facilitator level.

For this purpose, we propose the Three-Tetrahedron Model (3T-Model) for contentrelated PD research (Prediger et al. 2017), which incorporates existing multi-level and multifaceted PD research models. It was developed in the joint research activities at the German Center for Mathematics Teacher Education (DZLM).

In this article, which looks at mainly programmatic and structural aspects, the model is used to identify three strategies for generating relevant research and design approaches and to discuss how each of them informs the facilitators' work. In the following, we illustrate our arguments by examples from PD research. 


\section{Introducing the Three-Tetrahedron Model for content-related PD research}

In order to systematize existing research and identify gaps in relevant research that could inform facilitators, a model is required that grasps the complexity of content-related teaching and learning on the classroom, teacher, and facilitator level. We argue that it is useful to start with frameworks and principles on the classroom level (next subsection) and to then extend these to the levels of teacher and facilitator PD (subsequent subsection).

\section{The didactical tetrahedron: a multifaceted, content-related perspective on the complexity of learning and teaching in the classroom}

On the classroom level, research and development in the area of learning and teaching mathematics has always stressed that we need to pay attention to both a generic (content independent) and a content-specific perspective. In their often-cited meta-study on classroom interventions, Seidel and Shavelson (2007) showed that the most effective teaching interventions focus on content-specific aspects, not only on generic issues. Research on the classroom level has generated subject-specific and content-related instructional theories that have contributed to understanding learning processes and designing instructional settings (Sierpinska and Kilpatrick 1998; Gravemeijer and Cobb 2006).

In order to grasp the complexity of content-related aspects of teaching and learning, the commonplace didactical triangle is a classical model that relates the teachers, the students, and the mathematics classroom content (Fig. 1, left). In order to take into account the role of external resources, the didactical triangle has been extended to a tetrahedron by several authors, for example, to add digital tools (Ruthven 2012) or more generally curriculum resources (Cohen et al. 2003; Rezat and Sträßer 2012). In the context of developing and scaling up content-related PD, the vertex of resources is of particular interest as it is the easiest to "hand over" to teachers. However, good teaching requires not only well-designed resources but includes the whole complexity of classrooms. Research on different aspects of this classroom complexity has revealed multifaceted insights into the complex interplay of these four elements or only some of them. We adopt this view by considering classroom resources as a relevant aspect to capture teaching and learning from a content-related perspective and include it as the fourth vertex in the didactical tetrahedron (Fig. 1, right).
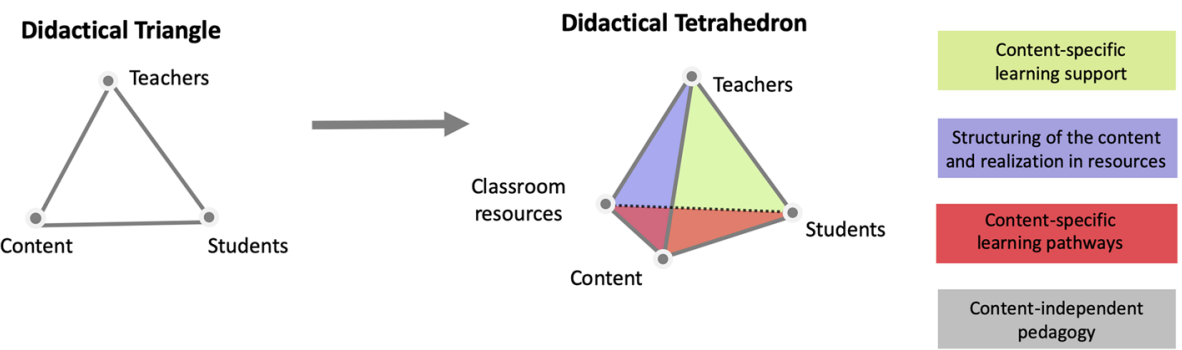

Fig. 1 Extending the didactical triangle to the didactical tetrahedron in order to grasp multifaceted complexities 
The tetrahedron model allows the consideration of not only the vertices but also the edges and especially the faces:

- The right face relates the teacher, the students, and the content in terms of contentspecific learning support.

- The left face relates the teacher, the resources, and the content in terms of y structuring the content and drawing on the respective resources.

- The lower face relates the students, the resources, and the content with respect to content-specific learning pathways.

- The back face relates the teacher, the students, and the resources in terms of contentindependent pedagogical aspects.

This interpretation of the faces emphasizes a dynamic view of the occurring processes in the classroom. In the next section, we explore whether and how the didactical tetrahedron serves to capture teaching and learning in the context of PD.

\section{Nested tetrahedrons on three levels: a multi-level perspective on the teaching and learning in PD}

Zaslavsky and Leikin (2004), Carroll and Mumme (2007), and Ball (2012) proposed shifting the didactical triangle from the classroom level to the teacher PD level. We adopt this view for the didactical tetrahedron because for the teacher PD level (TPD), the same four elements are crucial:

- The teachers (marked by $\mathrm{T}$ in Fig. 2), who, in their role as PD participants, are the learners on this level,

- The facilitators (F), who take the role of teacher educators within the PD context,

- The TPD content (TC), in other words, the aspects of mathematics teaching and learning that are addressed in the PD course, and

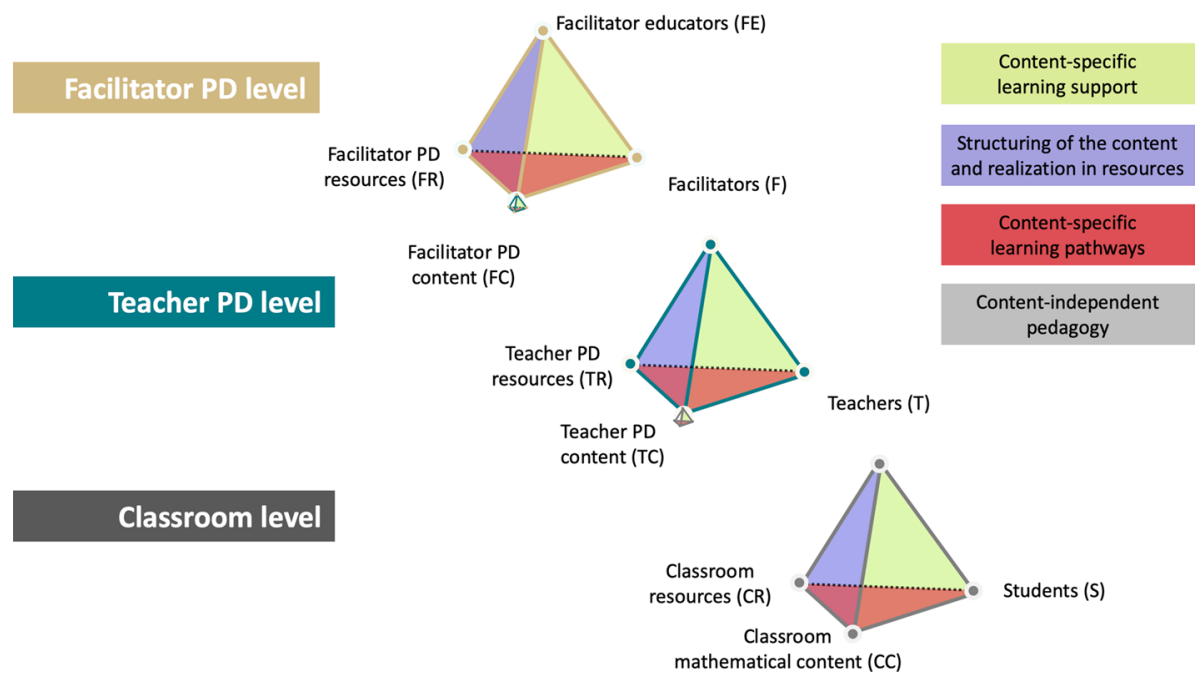

Fig. 2 Three-Tetrahedron Model (3T-Model) for content-related PD research (Prediger et al. 2017) 
- The TPD resources (TR) used in the PD course, for example, teaching artifacts or student solutions to specific tasks.

This parallelism provides the frame for a multifaceted approach to research on PD: The strength of subject-specific and content-related perspectives can and should be shifted to the level of teacher learning in PD situations. Hence, parallel models for grasping the complexity of teaching and learning can be applied (as many researchers have recently emphasized, e.g., Zaslavsky and Leikin 2004; Ball 2012; Karsenty and Arcavi 2017; TekkumruKisa and Stein 2017).

Finally, for the facilitator PD level (FPD), the same general tetrahedron structure can be used, which results in a model of three didactical tetrahedrons: the Three-Tetrahedron Model (3T-Model) as printed in Fig. 2.

There are several types of connections between the three levels that are useful for the design of and research on PD:

(a) Teachers and facilitators appear each in two roles, as educators and as learners. This double perspective can have a considerable impact on teachers' and facilitators' learning processes and can be used as a powerful component of PD programs (as emphasized by Borko et al. 2014).

(b) On all three levels, the faces of the tetrahedrons refer to structurally analogical foci:

- The right face relates the educator, the learners, and the content in terms of content-specific learning support.

- The left face relates the educator, the resources, and the content in terms of structuring the content and drawing on the respective resources.

- The lower face relates the learners, the resources, and the content with respect to the content-specific learning pathways.

- The back face relates the educator, the learners, and the resources in terms of content-independent pedagogical aspects.

(c) In terms of content, the model reveals nested structures: The TPD content encompasses aspects of the whole tetrahedron on the classroom level, and, analogically, the FPD content should take into account aspects of the whole tetrahedron on the TPD level (as already discussed by Zaslavsky and Leikin 2004; Carroll and Mumme 2007; Perks and Prestage 2008; Ball 2012; Luft and Hewson 2014; Wood and Turner 2015). The cited authors have suggested different triangular and tetrahedral models, each of them describing a self-similar nesting structure for two or three levels (the most similar to our approach is printed in Fig. 3).

The 3T-Model serves both designing and researching PD. Considering that the faces of the tetrahedrons refer to structurally analogical foci, design and research on the different levels resemble each other. PD design usually progresses from the bottom to the top by taking into account theoretical aspects and research findings from lower levels for the design on higher levels. PD research rather emphasizes the direction from the top to the bottom, for example, by deducing, postulating, and initiating processes and investigating their effects on different levels. As a synthesis, PD design research iteratively combines the bottom-up and top-down directions (Prediger 2019). 


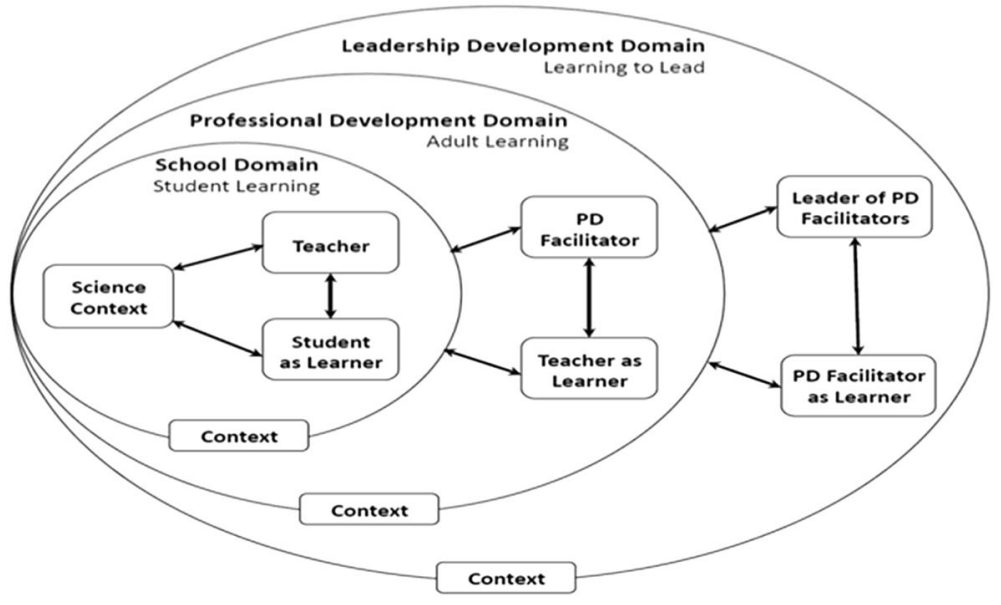

Fig. 3 Nested didactical triangles in the model of Luft and Hewson (2014)

\section{Research strategies within the Three-Tetrahedron Model}

The 3T-Model as introduced in the previous section should not be misunderstood as a "completist" research program. Hardly any research can manage to take into account all different facets and levels simultaneously. Instead, PD researchers have adopted different strategies to consider the multi-level structure and to foreground some faces while keeping others in the background. In the next subsection, we outline three main strategies by which current PD research has realized a multi-level perspective, which we call the lifting, the nesting, and the unpacking strategies.

After this general introduction, the two subsequent subsections provide examples where the 3T-Model is used to analyze two examples of PD design and research, where the three strategies were used implicitly or explicitly by the researchers and locate the foregrounded facets in the three tetrahedrons. In a more overarching approach, the model can be used to understand existing PD research studies and their location, thereby showing the gaps they still leave.

\section{Three strategies for setting PD research agendas dealing with the multi-level structure of PDs}

By studying the existing literature on PD research and analyzing it with regard to possible gaps, we identified three general strategies for designing PD and generating relevant research questions, addressing the multi-level structure of PD (see Fig. 4).

(1) A lifting strategy, by which design and research approaches are lifted from the classroom level to the TPD level or to the FPD level. This strategy draws upon the structurally analogous foci of the faces of the tetrahedrons, which allows for using structural analogies of content-related design and research on the three levels. In brief, lifting a design approach means that design principles or design elements developed for the 


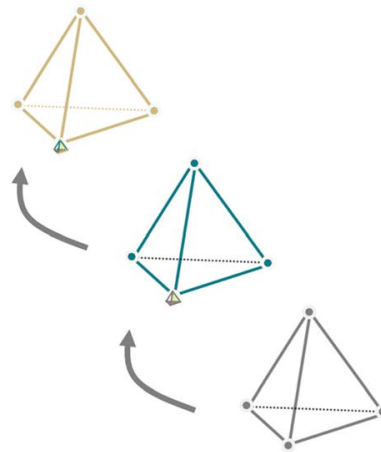

Lifting strategy for PD design and PD research

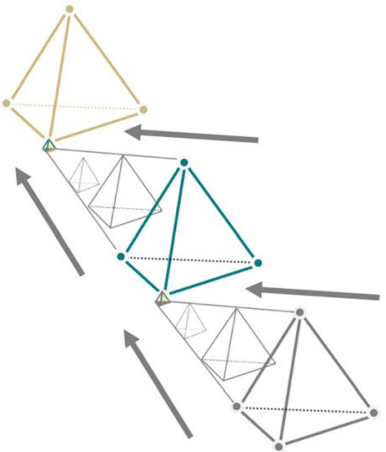

Nesting strategy

for PD design

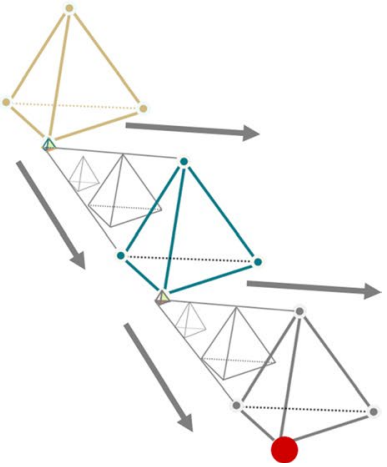

Unpacking strategy

for PD research

Fig. 4 Three strategies for setting research agendas in the multi-level structure

classroom level are implicitly or explicitly transferred (and adapted) to the TPD level (or from the TPD to FPD level). Lifting a research practice means that certain types of research questions and/or methods from the classroom level are implicitly or explicitly transferred (and adapted) to the TPD level (or from the TPD to FPD level) and applied in an analogous way.

(2) A nesting strategy for a research-based PD design, which takes into consideration that, during the design, aspects of the complete classroom tetrahedron (aspects of all vertices and edges) should be nested in the TPD content and aspects of the complete TPD tetrahedron should be similarly nested in the FPD content. This design strategy accounts for the holistic challenges of PD and addresses multifaceted complexitieswithout claiming any completeness. In brief, the nesting strategy builds the PD design upon the idea of structuring the TPD/FPD content in a self-similar nested structure, taking into account the complexities of the tetrahedrons below.

(3) An unpacking strategy for content-related, design-based PD research which, during research, unpacks the PD content on the TPD level (or the FPD level) with respect to the elements of the respective tetrahedrons of the levels below, for instance, when investigating how facilitators' knowledge grows during the FPD on the different levels and with respect to different vertices and faces of different tetrahedrons. This research strategy specifically emphasizes the relevance of content-specific research underpinning the chosen design.

\section{The lifting strategy}

The lifting strategy capitalizes on the structural analogies between the three levels, that is, the analogous facets of teaching and learning. It is applied when successful design and research approaches are appropriated on the next level for the analogical facets and with structurally analogical questions, instruments, and methods (as, for example, by Jackson et al. 2015). This especially applies to approaches for investigating the phenomenology of teaching and learning of specific content and to theoretical frameworks that can be used as lenses for such research: 
- Design approaches drawing on video-based material to support teachers' noticing of relevant classroom incidents can be lifted from the TPD level to the FPD level to help facilitators developing their noticing of teacher learning. Thereby, design elements such as structured or unstructured video clubs can be based on findings on the TPD level (van Es and Sherin 2008).

- Research approaches for investigating students' conceptions and learning pathways for a specific mathematical content (by interview studies or design experiments) can be lifted to the PD level by investigating teachers' conceptions and learning pathways for a specific PD content area such as language responsiveness in mathematics classrooms (e.g., Smit and van Eerde 2011; Prediger 2019). This resonates with the call for more process focus for teacher learning pathways by Goldsmith et al. (2014).

- Research approaches investigating teachers' classroom practices can be lifted to the PD level to allow for exploring facilitators' teaching practices. This has been done, for example, for facilitation moves (e.g., Stein et al. 2008; Tekkumru-Kisa and Stein 2017). That is, theoretical frameworks are first moved one level up to guide the research.

Most projects applying the lifting strategy for setting the design or the research agenda can exploit the structural analogies, but at the same time experience its limitations since teachers as learners are different from students as learners, and PD content is usually more complex than classroom content. In order to account for this higher complexity, nesting and unpacking strategies are important.

\section{The nesting strategy}

As the PD content on the TPD level usually encompasses aspects of the complete classroom tetrahedron (and the FPD content consequently aspects of all vertices of both tetrahedrons), the nesting strategy builds the PD design upon the idea of capturing this complexity in a self-similar nested structure (e.g., Zaslavsky and Leikin 2004; Carroll and Mumme 2007; Perks and Prestage 2008; Ball 2012; Luft and Hewson 2014; Wood and Turner 2015) and of exploiting the research findings in the tetrahedrons below for shaping the TPD and FPD content. This provides the opportunity, for example, to rely on research results for the classroom level in order to specify the TPD content:

- When designing a TPD for a specific classroom innovation (e.g., using digital tools for exploring algebra), the PD also has to relate to students' typical learning pathways in exploratory situations and to misconceptions for algebra.

- Analogically, the FPD preparing for leading such a PD course should take into consideration all relevant aspects on the classroom level, but also activities by which the teachers can reflect on these issues and empirical insights into typical teacher learning pathways, such as typical challenges that teachers face when implementing these exploratory situations in their algebra classrooms.

These examples show that the nesting strategy for research-based design imposes research questions: When teachers' learning pathways toward digital tools in algebra classrooms are considered to be a relevant part of the nested FPD content, then they should be investigated. First, for example, when designing a TPD for teaching in heterogeneous mathematics classrooms, one can exploit the research on the classroom. However, when specifying the content of the $\mathrm{PD}$, one realizes that although there is research on, for instance, the 
effectiveness of student grouping strategies (Slavin 1987; Deunk et al. 2015), there are only few empirical findings on content-specific whole-class differentiation (e.g., Klieme et al. 2009, on the Pythagoras theorem). Thus, such content-specific research is required in order to inform facilitators on the nesting strategy, which draws on research-based design aspects for the PD level.

On the second level, specific empirical insights are required into how teachers can best be introduced to these content-specific whole-class differentiations in their mathematical topic. Again, the nesting strategy for research-based design imposes new research questions, also on the TPD level.

So far, the nesting strategy has been introduced in the literature in a rather generic way without specifying what nesting means given that a specific content area is subject of the PD. From our viewpoint, the nesting strategy indicates research gaps on the levels below, which should be closed in order to inform the content specification in the research-based design of PD courses.

\section{The unpacking strategy}

Before generally describing the research strategy of unpacking, the example of designing PD for a specific classroom innovation from above is continued: A content-related research approach investigating the effects of a designed FPD course not only asks generic questions on facilitators' general acceptance of the classroom innovation but unpacks different aspects from the FPD content in order to capture what the facilitators drew from the FPD and might implement in their PD practices. This will refer not only to mathematical knowledge about exploring mathematical theorems but also to knowledge about typical classroom tasks (knowledge about CR) and facilitators' knowledge about teachers' typical learning pathways when implementing the explorations (TC-T and T-CR).

This shows the complementarity of lifting and unpacking strategies: Whereas the lifting strategy exploits the structural analogies for design and research but treats every learning content in an unpacked way, the unpacking research strategy takes into account the nestedness of the PD content and goes down to aspects of the tetrahedrons below. For example, the necessary facilitation moves in TPD might not be the same in classrooms as the PD content is much more complex than the classroom content and takes into account the mathematical classroom content as well as didactical aspects on learning the mathematical content. Hence, the strategy of unpacking the nested PD content is fundamental to allowing the PD research to be really content specific rather than only generic. By unpacking the PD content along the tetrahedrons, a language is provided for capturing the complex interplay of different aspects. This is specifically important for design-based PD research but is also important for content-related PD research that does not start from a design perspective.

Although the three strategies can be distinguished structurally, they usually appear in intertwined ways in many research projects. In the following two sections, we provide examples and discuss how the 3T-Model enables disentangling the elements of PD design and research and the respective strategies in these projects. 


\section{An example for existing research in lifting, nesting, and unpacking strategies between the classroom and TPD tetrahedrons}

An example for PD research that intertwines the different strategies is Swan's (2007) often-cited paper on a task-based PD. As Fig. 5 illustrates, its focus can be located in the 3T-Model (here only the two lower tetrahedrons).

The starting point for the PD, extensively described in Swan (2007), was the researchbased design of rich algebra tasks (including video clips showing the tasks in use), which were developed in order to foster low-achieving students' algebraic understanding. This classroom resource (CR) was iteratively optimized to engage students in cognitively demanding mathematical activities and rich mathematical discussions. The material was then used to initiate change in teaching practices of the 44 teachers, who had participated in 4-day PD program, spread over 6 months. After an initial phase of reflecting the participants' contexts for working, the task types were introduced and discussed, and in a later session, the teachers' experiences in adapting and using the tasks were shared.

The paper as a whole delivers the core message that the careful design of classroom resources (CR) can be an important tool for PD courses to represent the real or intended practice on the classroom level. Tasks are typical classroom resources, and here they are also considered a major element of TPD, as they can engage teachers in the important activity of experimenting with these tasks in their own classrooms and thus become integrated in TPD resources (TR). Hence, the main design focus for the PD was designing rich activities around the tasks and videos. The strategy visible in this PD amounts to the author having lifted his own major design focus (engaging learners in rich activities) from the classroom to the TPD level-without the author stating so explicitly in their reports. The fact that he also included videos from classroom situations in which students worked on the tasks shows how he nested the classroom tetrahedron in the PD content: Not only the tasks as resource, but also practices of dealing with the tasks were considered by the nesting strategy for design.

The PD research reported in the paper corresponds to a second lifting strategy, this time for research. Rather than considering what students learned by the activities (lower face CR-CC-S), which is a typical research perspective in design research, the research accompanying the PD investigates what teachers learned during the PD (lifted lower face

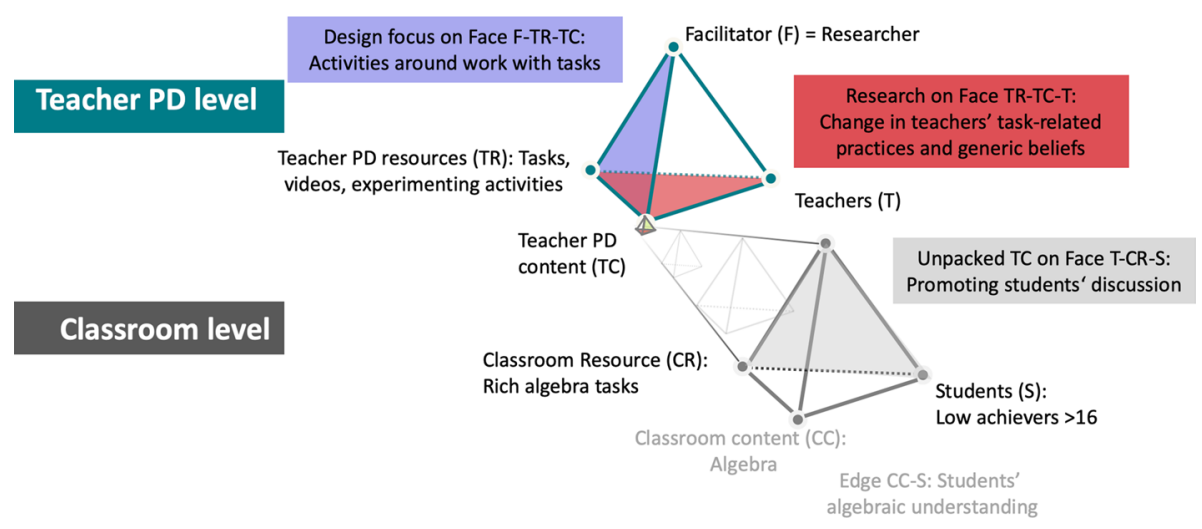

Fig. 5 Locating Swan's (2007) design and research approach on task-based PDs 
TR-TC-T). However, due to the nesting of the PD content (TC), the research cannot be organized in strict parallelism because it has to take into account the much more complex character of the TPD content (TC). In this paper, the unpacking amounts to conceptualizing teacher learning as change in teacher practices and teacher beliefs, which is captured by questionnaires and interviews. A deeper way of unpacking could have included the learning of students, e.g., by analyzing products from the classrooms of the PD participants.

The interesting question is how the nested TPD content is unpacked in order to capture this change. A careful reading of the paper shows its limitation in this respect: Beliefs are only considered in a generic way, addressing mathematics (CC), teaching (whole tetrahedron), and learning (lower face CC-CR-S) with respect to transmissive, connectionist, and discovery stances. The practices are captured more content specifically with respect to the tasks (back face CR-T-S), but without explicitly taking into account aspects of algebra learning (in the lower edge $\mathrm{CC}-\mathrm{S}$ ). In this way, the unpacking remains restricted to generic aspects and does not include the focus on the mathematical learning content (CC). For the purpose of informing facilitators, however, the teachers' change with respect to algebra learning would have also been of great interest.

The preceding analysis showed how locating the focus of the research within the 3T-Model enables us to structurally understand the research approaches, the intertwinement of applied research strategies, and how to identify potentially important gaps in the research.

\section{An example for existing research in lifting, nesting, and unpacking strategies between the classroom, TPD, and FPD tetrahedrons}

An example for FPD design and FPD research that (implicitly or explicitly) combined the different strategies is Borko et al.'s (2014) multi-year design research project on FPD to promote the Problem-Solving Cycle in TPD. Figure 6 shows how the focus of the project can be located in the 3T-Model and how all three levels are integrated.

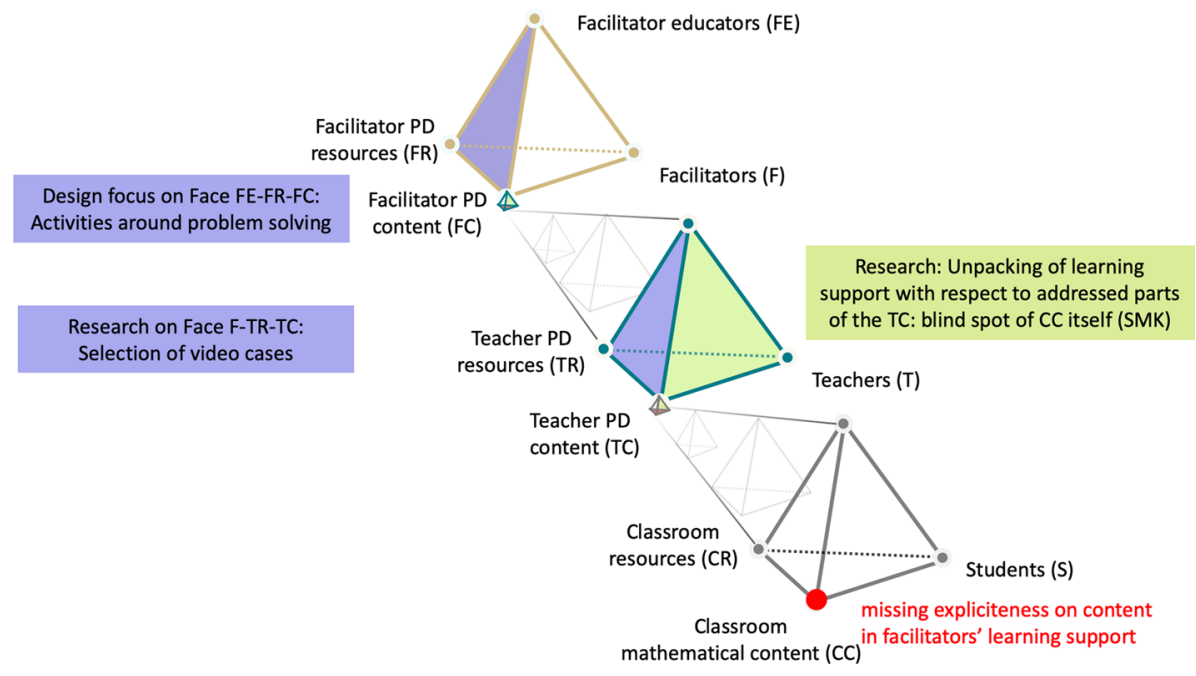

Fig. 6 Locating Borko et al.'s (2014) design and research approach on the Problem-Solving Cycle 
The TPD activities in the Problem-Solving Cycle approach include multiple cycles of interconnected PD workshops that center around mathematically rich tasks. In each cycle, teachers first solve the given problem on their own and develop a lesson plan for teaching it in their classrooms that considers their students' specific learning needs. The teachers then implement the problem, immerse their students in solving it, and videorecord the classroom situation. The TPD facilitator carefully selects video clips that show key examples of both teacher instruction and student thinking. The video clips take a prominent role within the TPD as they are used as starting point for discussing how to elicit and build upon student thinking and what instructional aspects push students toward the learning goals.

The preparation of teacher leaders to facilitate the Problem-Solving Cycle included two and a half years of courses and support in changing the role from teacher to facilitator. The specific design of the facilitator preparation was developed and investigated in a multiyear design research project. In the FDP, the novice facilitators were also immersed in the Problem-Solving Cycles described above, so the designers adopted a lifting strategy for the design. In addition, the FPD comprised a summer leadership academy to initially introduce the key characteristics. Also, when conducting the TPD on their own, the facilitators received ongoing support from the research team.

Preparing the facilitator to lead such a TPD with the Problem-Solving Cycle with integrity was based on the following key characteristics: using a rich mathematics problem and involving teachers in the solution process; facilitating productive discussion on the mathematics content, students' thinking, and instructional practices; focusing the discussions on diverse representations and solution strategies; and carefully selecting video clips from teachers' classroom practice.

As overarching design element, it is clear that the Problem-Solving Cycle as a teaching approach has been lifted from the classroom to the teacher and facilitator PD level to immerse teachers and facilitators in discussing tasks they first approached themselves. Carefully designed tasks serve as resources to engage students (classroom resources CR), teachers (TPD resources TR), and facilitators (FPD recourses FR) in rich mathematical discussions (and address them in their double roles as educators and learners). Both approaches of implementing the Problem-Solving Cycle on the PD level and the classroom level are grounded on prior research that provides empirical evidence for positive effects on student learning.

In addition, the project designers implicitly drew on the nesting strategy for specifying the TPD content as they to consider all faces of the classroom tetrahedron in the PD: The face of content-specific learning support (right face on classroom level) is integrated through videotaping teachers' classroom instruction, and the content-specific learning pathways are displayed by the students' artifacts the teachers collected and also what could be observed in the selected video cases (lower face of the classroom level). The structuring of the content (TC) and the realization of resources (TR) was particularly embedded in the TPD design as teachers developed a lesson plan together during one of the sessions. The nesting strategy can also be observed for the design on the FPD level, as the tetrahedron on the TPD level was additionally taken into account to specify the FPD content. Using minicases to simulate implementation of the Problem-Solving Cycle, the facilitators' discussion was directed to the interplay of teacher learning and instructional practices.

The dominant research strategy in this study was unpacking from the FPD to the TPD level. Besides investigating whether the main program goals were reached in the ProblemSolving Cycle the facilitators provided, the research concentrated on unfolding what characteristics of the approach on the TPD level were enacted particularly well or inadequately: 
The facilitators performed well on sustaining a professional learning community (content-independent pedagogy) and were able to select videos to enact rich discussions on important aspects relevant to classroom practice (TR). Regarding the latter, a facilitator's guide providing key characteristics of "rich" video clips and instructional support meetings where the selection of video cases could be probed together with colleagues proved to substantially inform facilitation practice.

However, the research shows limitations with respect to TPD content enacted by the facilitators: The facilitators had difficulties in "support[ing] deep analysis in discussions to foster both SCK [specialized content knowledge] and aspects of PCK [pedagogical content knowledge]" including knowledge of content and students ... and knowledge of content and instruction" (Borko et al. 2014, p. 164), indicating that they struggled with providing content-specific learning support (right face on the PD level) for the participants of their PD with respect to the mathematical content itself (CC). The researchers concretized that although the FPD included many opportunities to facilitate such "high-press exchanges," the participating facilitators struggled with "engaging teachers in discussions about the relationships, affordances, and constraints of representations and solution strategies" (ibid., p. 164). Grasping these limitations was only possible by the (implicit) research strategy of unpacking the PD content (TC) into its component of the classroom tetrahedron (of course, phrased in other terms by Borko et al. 2014).

In light of the 3T-Model, one could infer that more insights into teachers' contentspecific learning pathways could have informed the facilitator preparation in this respect. Again, unpacking seems to be a valuable research strategy for identifying these possibilities and to draw consequences for the FPD content which transcend the simple lifting strategy for design and take into account the nested structure of PD contents. In this way, lifting, nesting, and unpacking can be combined.

\section{An example for setting PD design and research agendas by means of the lifting, nesting, and unpacking strategies}

The previous sections provided examples of how the strategies within the 3T-Model can be used to analyze existing PD design and research approaches. Beyond this, their main strength is to support the process of inspiring and setting PD design and research agendas. In the following example, we illustrate how in one of our current research projects the strategies in the 3T-Model can help find research questions for studies that inform and support PD facilitators. To this purpose, we continue the example of a PD course dealing with heterogeneity and focus on the topic of fractions.

\section{Specifying the content on the TPD and the FPD level by applying the nesting strategy}

In line with the nesting strategy, the TPD course should cover aspects of all faces of the classroom tetrahedron. To develop a research-based design, PD designers should search for research literature on questions such as:

- What is known about classroom pedagogies for dealing with heterogeneity? (back face of the classroom tetrahedron generically, without taking into account the subject of fractions as specific content). 
- Which research studies provide insights into students' heterogeneous learning pathways toward fractions, and how can these pathways be best supported? (lower face of the classroom tetrahedron).

- Which research findings can give information on adequate teaching practices for providing learning support in differentiated fraction classrooms? (right face).

- Which research findings on mathematical tasks and which research-based textbooks and hands-on material for fractions exist, and how can they support dealing with heterogeneity in the classroom when dealing with fractions as content? (left face of the classroom tetrahedron both generic and specifically for fractions).

These and other possible questions need to be answered first, in order to provide evidence for the TPD design. Research gaps that eventually occur on the classroom level should be filled before starting any PD course. Most of the research gaps are likely to occur in the concrete mathematical content, in this case, fractions (see Lamon 2007 for a research overview on fractions), and how to apply differentiated approaches that support students' learning of the topic.

When shifting to the design on the FPD level, the nesting strategy then continues to play a crucial role. The following questions are decisive:

- Which aspects of the findings are relevant for teachers and why? For example, results on the achievement effects of grouping (such as Slavin 1987) do not inform teachers about concrete teaching strategies, whereas teaching experiments in algebra such as Swan (2007) do.

- Which of the aforementioned findings are useful or necessary to inform PD facilitators as background knowledge for the explicit TPD content? For example, research on teacher beliefs on students' algebra development (Nathan and Koedinger 2000) can help identifying prerequisites of participants. However, teacher change during PD has been investigated generically, but much less with respect to the algebra curriculum (e.g., Hough et al. 2007).

For the FPD content, further relevant research-based knowledge can be identified, in line with the nesting strategy, that alludes to the following issues:

- What is known about mathematics teachers' practices and experiences with respect to dealing with heterogeneity?

- What are teachers' typical learning pathways throughout the TPD content?

- How can all aspects to be learned be structured within a TPD course?

\section{Designing the PDs on TPD level and FPD level by applying the lifting strategy}

To develop the concrete design of the PD for teachers or facilitators, the specified content is then structured by appropriate activities and inputs. Here, the lifting strategy can generate many relevant research questions for a research-based design, for instance:

- Which PD activities can engage teachers or facilitators in rich discussions on aspects of heterogeneous fraction classrooms?

- Which learning support is necessary for developing teachers' or facilitators' knowledge? 
Here, many relevant findings of generic PD research can be taken as a starting point (see Timperley et al. 2007) and then be refined for the specific PD content (in this case, for facilitators) in view. For a research-based refinement, the unpacking strategy is crucial in order to grasp the aspects of the specific PD content.

\section{Researching content-related aspects of the PD by the unpacking strategy}

There is general consensus in the importance of the PD content focus, particularly on "the link between activities that focus on subject matter content and how students learn that content" (Desimone 2009, p. 184), which is decisive for increases in teacher knowledge and skills and improvements in practice. However, this recommendation has mostly been treated only on a surface level. Many PD research studies have treated the PD content as one inseparable block, so the findings have been more generic on such things as the benefits of reflection and teacher forming learning communities. To inform the design in a more content-specific way, the PD content must be unpacked into the separate aspects of the underlying tetrahedron:

- Which PD activities can engage teachers in reflections on students' heterogeneous learning needs?

- Which PD activities can engage teachers in reflections on teaching practices for addressing talented students' enriched fraction knowledge?

The unpacking can be done systematically by relating the vertex PD content (TC) to the other vertices of the PD tetrahedron. The exploration of every link with respect to PD design and PD research is then guided by different questions.

The same applies to the FPD level. Thus, the unpacking strategy helps to relate design and research in view of the focus set within the 3T-Model. Among others, the following research questions help to inform the PD facilitator design:

- Which activities can help facilitators to be prepared for the different experiences the teachers bring into PD courses on how to introduce fractions in the differentiated classroom?

- Which knowledge on dividing fractions from a mathematical viewpoint do facilitators need to be able to adequately support teachers' choices of differentiated approaches?

- How can resources on exemplary instructional strategies for fractions be best designed to ensure fidelity when facilitators use them in TPD?

The example discussed in this section points out the relevance of the unpacking strategy in revealing the content-related aspects of PD for teachers and facilitators. In interplay with the nesting and lifting strategies, the research focus on the teaching and learning of a specific mathematical content unfolds its real-life complexity through unpacking. 


\section{Discussion}

On the theoretical level, many frameworks have emerged to capture the complexity of PD. We consider the specific value of our contribution to this field to be the identification and description of recurring strategies that enable designers and researchers to analytically look at PD and to apply a special focus on the content. As an analytical framework, we suggest the multifaceted structure of teaching and learning (via the tetrahedron) and the parallelism of the student, teacher, and facilitator levels (via the three-level structure). In addition to this rather static structural view, we propose a dynamic view of the strategies that scholars commonly apply when they make decisions in their design and research activities.

Particularly, we contend that PD design and research approaches should take into account the multifaceted and multi-level character of the field in an explicit manner. Therefore, many different researchers have developed variants of the lifting strategy, which builds upon the structural analogies between the facets in each tetrahedron (e.g., Zaslavsky and Leikin 2004; Ball 2012). When focusing on TPD or FPD design, some have also mentioned variants of the nesting strategy or the self-similar nested structures (e.g., Zaslavsky and Leikin 2004; Carroll and Mumme 2007; Perks and Prestage 2008; Ball 2012; Luft and Hewson 2014; Wood and Turner 2015). In this paper, we combined the different ideas within the 3T-Model in which the strategies can be explicitly defined and affordances and limitations can be discussed. By locating the core ideas in the 3T-Model, we intended to contribute to what Luft and Hewson (2014) asked for: "First, we must be more strategic in our research endeavors... Some forms of research in the field ... are no longer useful. ... For instance, it would be useful to know how teachers learn about a concept as they engage in a PD program, and how specific strategies best support teacher learning and student learning. As PD researchers move forward, they must clarify how the proposed research addresses some problem" (p. 62).

By introducing a third strategy, the unpacking strategy, we gave some additional answers to the question of which kind of research can support PD facilitators, focusing on the need to go back to content-related aspects on the lower levels to account for the nested structure not only in design, but also in the research.

Locating the different research strategies in the 3T-Model for content-related PD research allows for aligning the following aspects:

- Taking into account the PD complexities in a multifaceted and multi-level perspective,

- Understanding specific design and research approaches and analyzing to what exactly they contribute,

- Identifying in which aspects content relatedness is crucial for the design and research approaches, and, finally,

- Providing a language for discussing research approaches across different research groups.

While discussing examples, the strategies have been shown to be complementary in different ways: The lifting strategy can produce generic PD designs, and the nesting strategy accounts for the relevance and depth of the content-specific aspects. The nesting strategy on the other hand considers the multi-level character on the design side, while the unpacking strategy takes the multi-level character into account in the content-related research. As a whole, the three strategies in the 3T-Model can help to locate existing research, to identify gaps, and to generate further research questions for content-related PD research. 
Especially for the challenge of specifying the TPD and FPD contents as raised by Garet et al. (2016), the nesting strategy provides a first approach. The unpacking strategy then helps, in a second step, to create the research base for refining the PD content details.

However, their limitations must also be made explicit: Generating research questions alone does not determine good and useful research that really supports PD facilitators. Of course, good research also depends on suitable research methods and a good PD design, which were not in the scope of this article.

While the content focus that accompanies the tetrahedral view that is brought along with the 3T-Model can help to highlight and consider content-related aspects of PD research and design, we admit that this may also risk a drawback: The 3T-Model focuses only on four facets of teaching and learning while neglecting the context, for instance, the conventions and norms on student learning or institutions (see Rezat and Sträßer 2012). This could be included in more elaborated versions.

This article has only presented a general framework for looking at PD in a systematic way. During our own work, our understanding of the structure of the 3T-Model and the strategies of navigating within the model gradually developed. We are confident that in future research and development it will prove useful, but also that it may develop and differentiate in further directions.

Acknowledgements The paper grew within the collaboration of the authors with other colleagues in the DZLM (German Center of Mathematics Teacher Education), which is financially supported by the German Telekom Foundation.

Open Access This article is distributed under the terms of the Creative Commons Attribution 4.0 International License (http://creativecommons.org/licenses/by/4.0/), which permits unrestricted use, distribution, and reproduction in any medium, provided you give appropriate credit to the original author(s) and the source, provide a link to the Creative Commons license, and indicate if changes were made.

\section{References}

Ball, D. L. (2012). Afterword: Using and designing resources for practice. In G. Gueudet, B. Pepin, \& L. Trouche (Eds.), From text to 'lived' resources (pp. 349-359)., Mathematics curriculum materials and teacher development Dordrecht: Springer.

Borko, H., Jacobs, J., Eiteljorg, E., \& Pittman, M. E. (2008). Video as a tool for fostering productive discourse in mathematics professional development. Teaching and Teacher Education, 24(2), 417-436.

Borko, H., Koellner, K., \& Jacobs, J. (2014). Examining novice teacher leaders' facilitation of mathematics professional development. The Journal of Mathematical Behavior, 33, 149-167.

Carroll, C., \& Mumme, J. (2007). Learning to lead mathematics professional development. Thousand Oaks: Corwin.

Cobb, P., Confrey, J., diSessa, A., Lehrer, R., \& Schauble, L. (2003). Design experiments in educational research. Educational Researcher, 32(1), 9-13.

Cohen, D. K., Raudenbush, S. W., \& Ball, D. L. (2003). Resources, instruction, and research. Educational Evaluation and Policy Analysis, 25(2), 119-142.

Desimone, L. M. (2009). Improving impact studies of teachers' professional development: Toward better conceptualizations and measures. Educational Researcher, 38(3), 81-199.

Deunk, M. I., Doolaard, S., Smalle-Jacobse, A., \& Bosker, R. J. (2015). Differentiation within and across classrooms: A systematic review of studies into the cognitive effects of differentiation practices. GION onderwijs/onderzoek: Rijksuniversiteit Groningen.

Even, R. (2005). Integrating knowledge and practice at MANOR in the development of providers of professional development for teachers. Journal of Mathematics Teacher Education, 8(4), 343-357.

Garet, M. S., Heppen, J. B., Walters, K., Smith, T. M., \& Yang, R. (2016). Does content-focused teacher professional development work? Findings from three Institute of Education Sciences Studies (NCEE Evaluation Brief 2017-4010). Washington, D.C.: U.S. Department of Education, Institute of Education 
Sciences, National Center for Education Evaluation and Regional Assistance. https://ies.ed.gov/ncee/ pubs/20174010/pdf/20174010.pdf. Last accessed 31 March 2019.

Goldsmith, L., Doerr, H., \& Lewis, C. (2014). Mathematics teachers' learning: A conceptual framework and synthesis of research. Journal of Mathematics Teacher Education, 17(1), 5-36.

González, G., Deal, J. T., \& Skultety, L. (2016). Facilitating teacher learning when using different representations of practice. Journal of Teacher Education, 67(5), 447-466.

Gravemeijer, K., \& Cobb, P. (2006). Design research from a learning design perspective. In J. van den Akker, K. Gravemeijer, S. McKenney, \& N. Nieveen (Eds.), Educational design research: The design, development and evaluation of programs, processes and products (pp. 17-51). London: Routledge.

Hough, S., O'Rode, N., Terman, N., \& Weissglass, J. (2007). Using concept maps to assess change in teachers' understandings of algebra: A respectful approach. Journal of Mathematics Teacher Education, 10(1), 23-41.

Jackson, K., Cobb, P., Wilson, J., Webster, M., Dunlap, C., \& Appelgate, M. (2015). Investigating the development of mathematics leaders' capacity to support teachers' learning on a large scale. ZDM Mathematics Education, 47(1), 93-104.

Jacobs, J., Seago, N., \& Koellner, K. (2017). Preparing facilitators to use and adapt mathematics professional development materials productively. International Journal of STEM Education, 4(30), 1-4.

Jaworski, B., \& Huang, R. (2014). Teachers and didacticians: Key stakeholders in the processes of developing mathematics teaching. ZDM Mathematics Education, 46(2), 173-188.

Karsenty, R., \& Arcavi, A. (2017). Math, lenses and videotapes: A framework and a language for developing reflective practices of teaching. Journal of Mathematics Teacher Education, 20(5), 433-455.

Klieme, E., Pauli, C., \& Reusser, K. (2009). The Pythagoras study. Investigating effects of teaching and learning in Swiss and German mathematics classrooms. In T. Janik (Ed.), The power of video studies in investigating teaching and learning in the classroom (pp. 137-160). Münster: Waxmann.

Lamon, S. J. (2007). Rational numbers and proportional reasoning. In F. K. Lester (Ed.), Second handbook of research on mathematics teaching and learning (pp. 629-667). Charlotte: Information Age.

Lesseig, K., Elliott, R., Kazemi, E., Kelley-Petersen, M., Campbell, M., Mumme, J., et al. (2017). Leader noticing of facilitation in videocases of mathematics professional development. Journal of Mathematics Teacher Education, 20(6), 591-619.

Luft, J. A., \& Hewson, P. W. (2014). Research on teacher professional development in science. In S. K. Abell \& N. G. Lederman (Eds.), Handbook of research in science education (Vol. 2, pp. 889-909). New York: Routledge.

Nathan, M. J., \& Koedinger, K. R. (2000). An investigation of teachers' beliefs of students' algebra development. Cognition and Instruction, 18(2), 209-237.

Perks, P., \& Prestage, S. (2008). Tools for learning about teaching and learning. In B. Jaworski \& T. Wood (Eds.), The international handbook of mathematics teacher education (Vol. 4, pp. 265-280). Rotterdam: Sense.

Prediger, S. (2019). Promoting and investigating teachers' pathways towards expertise for language-responsive mathematics teaching. Mathematics Education Research Journal. https://doi.org/10.1007/s1339 4-019-00258-1.

Prediger, S., Leuders, T., \& Roesken-Winter, B. (2017). Drei-Tetraeder-Modell der gegenstandsbezogenen Professionalisierungsforschung: Fachspezifische Verknüpfung von Design und Forschung. Jahrbuch für Allgemeine Didaktik, 2017, 159-177.

Rezat, S., \& Sträßer, R. (2012). From the didactical triangle to the socio-didactical tetrahedron: Artifacts as fundamental constituents of the didactical situation. ZDM Mathematics Education, 44(5), 641-651.

Roesken-Winter, B., Hoyles, C., \& Blömeke, S. (2015). Evidence-based CPD: Scaling up sustainable interventions. ZDM Mathematics Education, 47(1), 1-12.

Ruthven, K. (2012). The didactical tetrahedron as a heuristic for analysing the incorporation of digital technologies into classroom practice. ZDM Mathematics Education, 44(5), 627-640.

Seidel, T., \& Shavelson, R. J. (2007). Teaching effectiveness research in the past decade: The role of theory and research design in disentangling meta-analysis results. Review of Educational Research, 77(4), 454-499.

Sierpinska, A., \& Kilpatrick, J. (Eds.). (1998). Mathematics education as a research domain: a search for identity., ICMI study 2 Dordrecht: Kluwer.

Slavin, R. E. (1987). Ability grouping and student achievement in elementary schools. A best-evidence synthesis. Review of Educational Research, 57(3), 293-336.

Smit, J., \& van Eerde, D. (2011). A teacher's learning process in dual design research: Learning to scaffold language in a multilingual mathematics classroom. ZDM Mathematics Education, 43(6-7), 889-900. 
Sowder, J. T. (2007). The mathematical education and development of teachers. In F. K. Lester (Ed.), Second handbook of research on mathematics teaching and learning (pp. 157-223). Charlotte: Information Age.

Stein, M. K., Engle, R. A., Smith, M. S., \& Hughes, E. K. (2008). Orchestrating productive mathematical discussions: Five practices for helping teachers move beyond show and tell. Mathematical Thinking and Learning, 10(4), 313-340.

Swan, M. (2007). The impact of task-based professional development on teachers' practices and beliefs: A design research study. Journal of Mathematics Teacher Education, 10(4-6), 217-237.

Sztajn, P., Borko, H., \& Smith, T. M. (2017). Research on mathematics professional development. In J. Cai (Ed.), Compendium for research in mathematics education (pp. 793-823). Reston: NCTM.

Tekkumru-Kisa, M., \& Stein, M. K. (2017). Designing, facilitating, and scaling-up video-based professional development: Supporting complex forms of teaching in science and mathematics. International Journal of STEM Education, 4, 27. https://doi.org/10.1186/s40594-017-0087-y.

Timperley, H., Wilson, A., Barrar, H., \& Fung, I. (2007). Teacher professional learning and development. Best evidence synthesis iteration. Wellington: Ministry of Education.

van Es, E. A., \& Sherin, M. G. (2008). Mathematics teachers' "learning to notice" in the context of a video club. Teaching and Teacher Education, 24(2), 244-276.

Wood, M. B., \& Turner, E. E. (2015). Bringing the teacher into teacher preparation: Learning from mentor teachers in joint methods activities. Journal of Mathematics Teacher Education, 18(1), 27-51.

Zaslavsky, O., \& Leikin, R. (2004). Professional development of mathematics teacher educators: Growth through practice. Journal of Mathematics Teacher Education, 7(1), 5-32.

Publisher's Note Springer Nature remains neutral with regard to jurisdictional claims in published maps and institutional affiliations. 